\title{
Hardness Development of Dual-cured Resin Cements through Different Thicknesses of Ceramics
}

\author{
Xiangfeng MENG, Keiichi YOSHIDA and Mitsuru ATSUTA \\ Division of Fixed Prosthodontics and Oral Rehabilitation, Nagasaki University, Graduate School of Biomedical Sciences, Na- \\ gasaki, Japan \\ Corresponding author, Keiichi Yoshida E-mail:keiichi@net.nagasaki-u.ac.jp
}

Received October 6, 2005/Accepted December 15, 2005

\begin{abstract}
This study investigated the Knoop hardness of a thin layer in three dual-cured resin cements (Linkmax HV, Nexus 2, and Variolink II HV) irradiated through or not through different thicknesses (1 through $5 \mathrm{~mm}$ ) of a machinable ceramic. Hardness was recorded at a series of time intervals up to five days, starting from the end of a light irradiation period. Increase in hardness was more rapid over the first 0.5 hour; thereafter it continued at a low rate until maximum hardness was attained. Ceramic thickness had a significant influence on hardness in all dual-cured resin cements, especially when ceramic thickness was more than $4 \mathrm{~mm}$. In addition, it was noted that the polymerization of Nexus 2 seemed to be more dependent on light exposure compared with the other two materials. Variolink II HV and Linkmax HV, on the other hand, seemed to indicate the potential of being compensated by chemical curing to some degree.
\end{abstract}

Key words: Hardness, Dual-cured resin cement, Ceramic thickness

\section{INTRODUCTION}

Most resin cements used currently to bond esthetic restorations are of dual-curing type. Dual-cured resin cements have been developed with a view to combining the desirable properties of both chemicalcured and light-cured resin cements - such as extended working time, wide range of color shades, rapid initial hardening, and further curing by the chemical catalyst.

Although the chemical-curing component is expected to ensure complete polymerization wherever light intensity is attenuated severely by restorative material and tooth, a number of studies showed that most commercial dual-cured resin cements still possessed limitations similar to light-cured ones. As a result, light intensity had to be increased and light exposure time extended in order to improve their hardness, degree of conversion, and bond strength ${ }^{1-5)}$. Moreover, it was found that their hardness had an inverse relation with the thickness of ceramics or composites $^{6,7)}$.

Some studies compared the polymerizing potential of dual-cured resin cements with three curing modes $^{3,4,6,8-12)}$. They found that whether dual-cured resin cements were light-cured directly or through ceramic or composite, they always achieved a higher hardness value and degree of conversion than chemical-cured-only mode and light-cured-only mode. In general, different manufacturers have their own ratio of chemical/light catalyst in dual-cured resin to reach the appropriate balance rate of light-curing and chemical-curing, polymerization efficiency, and color stability. Although the curing potential of chemical-cured and light-cured components vary greatly among brands, the chemical-curing potential of most brands is found to be insufficient.

Regarding the polymerization behavior of bulk cement for light-cured or chemical-cured resin, several studies ${ }^{8,12-15)}$ have measured its surface hardness as a function of post-irradiation time. It was found that surface hardness had a rapid increase in the first 30 minutes after light exposure or mixing, followed by a slow and continuous increase until optimum hardness after one day or one week, depending on the material studied and the prevailing test conditions, such as material thickness, light condition, and restoring temperature. Darr and Jacobsen ${ }^{16)}$ investigated the hardness development of dual-cured resin cements by direct light irradiation and by chemical curing only. It was found that hardness increased rapidly in the initial 30 minutes after light curing, while the non-irradiated chemically cured samples were too soft for testing in the initial 30 minutes. After this initial period, both groups advanced in hardness at a very similar rate over the next 24 hours $^{16)}$.

In a clinical situation, it is important to know the hardness of initial cure and when the resin cement would attain adequate hardness after cementing a ceramic restoration of any thickness. Not only are they critical to the proper initial management of the restoration (such as finishing and occlusal adjustment of restoration), they have a significant impact on masticatory force loading too. It is important for dual-cured resin cements to be capable of achieving a sufficient degree of hardening with light-curing. This is to ensure adequate polymerization of the 
cement layer that is not readily accessible to the curing light due to the thickness of the ceramic restoration. Therefore, the purpose of this study was to investigate the influence of machinable ceramic thickness on the hardness development of a thin layer of dual-cured resin cement with post-irradiation time.

\section{MATERIALS AND METHODS}

\section{Materials used}

Table 1 lists the materials used in this study.

Five thick machinable ceramic plates $(10 \times 8 \mathrm{~mm}$ squares with $1.05,2.05,3.05,4.05$, and $5.05 \mathrm{~mm}$ thickness) were prepared from CAD/CAM blocks (GN-I, Shade A3, GC Corp., Tokyo, Japan) using a lowspeed cutting saw (Isomet, Buehler Ltd., Lake Bluff, IL, USA). Prefabricated ceramic material was mainly composed of $\mathrm{SiO}_{2}, \mathrm{~K}_{2} \mathrm{O}$, and $\mathrm{Al}_{2} \mathrm{O}_{3}$, and the main precipitated crystal was leucite $\mathrm{K}_{2} \mathrm{O} \cdot \mathrm{Al}_{2} \mathrm{O}_{3} \cdot 4 \mathrm{SiO}_{2}$. Three dual-cured resin cements - Linkmax HV (LMHV, GC Corp., Tokyo, Japan), Nexus 2 (NX2, Kerr Corp., Orange, CA, USA), and Variolink II HV (VLIIHV, Ivoclar/Vivadent, Schaan, Liechtenstein) - were also prepared.

\section{Specimen preparation}

The ceramic plates were sanded to a flat surface by hand grinding on wet 320-, 400-, 600-, and 800-grit silicon carbide paper and cleaned ultrasonically in distilled water for five minutes. Final thickness of each ceramic plate was $1.0,2.0,3.0,4.0$, or $5.0 \mathrm{~mm}$. A piece of adhesive polyethylene tape with a circular hole $5 \mathrm{~mm}$ in diameter was positioned on the surface of each machinable ceramic plate to standardize the thickness of cement layer at approximately $50 \mu \mathrm{m}$. Equal amount of base and catalyst pastes were mixed with a plastic spatula on a mixing pad for 10 seconds according to the manufacturers' directions. Then, a small amount of product was placed on each ceramic surface within the circle. The ceramic plate with resin cement paste was placed on a clear microcover glass $(0.15 \mathrm{~mm}$ thickness, Matsunami Glass Ind. Ltd., Tokyo, Japan) over a zirconia ceramic block (2 $\mathrm{mm}$ thickness) to obtain a flat surface. In this manner, a thin layer of resin cement was sandwiched between each thickness of ceramic plate with an adhesive polyethylene tape and a microcover glass (Fig. $1)$.

The dual-cured resin cement material was polymerized through each thickness of machinable ceramic using a halogen visible light curing unit (Candelux VL-5, J Morita Mfg. Corp., Kyoto, Japan) with an intensity of $800 \mathrm{~mW} / \mathrm{cm}^{2}$ and an 11-mm tip for an irradiation time of 40 seconds. After curing, the adhesive tape was removed carefully from the ceramic surface. To establish a controlled hardness for each resin material, specimens were cured directly with visible light irradiation on the clear glass for $40 \mathrm{sec}-$ onds (i.e., not through machinable ceramic or $0 \mathrm{~mm}$ thickness). Each group contained five specimens.

Light transmittance through machinable ceramic Ten ceramic slices of different thicknesses - 0.5, 1.0, $1.5,2.0,2.5,3.0,3.5,4.0,5.0$, and $6.0 \mathrm{~mm}$ - were cut from CAD/CAM blocks using a low-speed cutting saw. Light intensity was measured using a curing

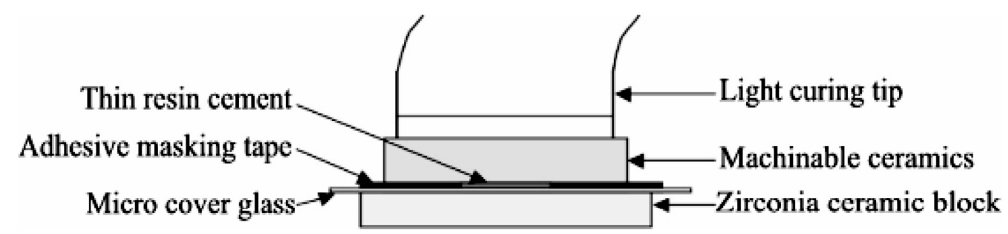

Fig. 1 Diagram of the experimental set-up to irradiate specimens through machinable ceramic.

Table 1 Materials used in this study

\begin{tabular}{|c|c|c|c|c|c|c|c|c|c|}
\hline \multirow{2}{*}{ Material } & \multirow{2}{*}{ Abbreviation } & \multirow{2}{*}{ Monomer } & \multicolumn{3}{|c|}{ Filler } & \multicolumn{2}{|c|}{ Initiator } & \multirow{2}{*}{ Shade } & \multirow{2}{*}{ Lot No. } \\
\hline & & & Content (wt\%) & $\operatorname{Size}(\mu \mathrm{m})$ & Type & Base & Catalyst & & \\
\hline Linkmax HV & LMHV & $\begin{array}{c}\text { UDMA } \\
\text { TEGDMA }\end{array}$ & 70 & 0.8 & F-Al-Si-glass & $\mathrm{CQ}$, amine & $\mathrm{BPO}$ & Brown (A3) & $\begin{array}{l}\text { Base: } 0501271 \\
\text { Catalyst: } 0501271\end{array}$ \\
\hline Nexus 2 & NX2 & $\begin{array}{c}\text { Bis-GMA } \\
\text { UDMA } \\
\text { TEGDMA }\end{array}$ & 68 & 0.6 & $\begin{array}{c}\text { Ba-Al-B-Si-glass } \\
\mathrm{SiO}_{2}\end{array}$ & $\mathrm{CQ}$, amine & $\mathrm{BPO}$ & Clear & $\begin{array}{l}\text { Base: } 420680 \\
\text { Catalyst: } 420680\end{array}$ \\
\hline Variolink II HV & VLIIHV & $\begin{array}{c}\text { Bis-GMA } \\
\text { UDMA } \\
\text { TEGDMA }\end{array}$ & 75.3 & 0.7 & Ba-Al-F-Si-glass & $\mathrm{CQ}$, amine & $\mathrm{BPO}$ & A3 & $\begin{array}{l}\text { Base: G14933 } \\
\text { Catalyst: G15148 }\end{array}$ \\
\hline
\end{tabular}

UDMA: urethane dimethacrylate; TEGDMA: triethyleneglycol dimethacrylate; Bis-GMA: bis-phenol-A-diglycidylmethacrylate; Al: aluminum; B: boron; Ba: barium; F: fluorine; Si: silicon; BPO: benzoyl peroxide; CQ: camphorquinone 
radiometer (Cure Rite, Dentsply Caulk, Milford, DE, USA) at wavelengths of $450 \pm 50 \mathrm{~nm}$ with a 6 -mm diameter sensor window. Visible light curing unit was activated for five seconds before any light reading was taken, allowing maximum light intensity to be attained. Maximum value was detected at 10 seconds of curing time at each of the 10 ceramic thicknesses. Linear regression analysis was applied to study the correlation between light intensity and ceramic thickness.

\section{Knoop hardness measurement}

For each layer of resin luting agent on the ceramic surface, five hardness measurements were recorded immediately after irradiation using a microhardness tester (MVK-E, Akashi Co. Ltd., Tokyo, Japan). A Knoop diamond indenter was applied under a load of $50 \mathrm{~g}$ for 30 seconds, and the length of the indentation's long diagonal was measured after the applied load was removed. Knoop Hardness Number (KHN) is inversely proportional to the square of the indentation's long diagonal. Further surface hardness measurements were recorded at post-irradiation times of $0.5,1,2,4,8,24,48,72$, and 120 hours. The specimens were stored dry in light-proof container at $25^{\circ} \mathrm{C}$ except during measurements. As indentation depth was less than $10 \mu \mathrm{m}$ and that calculation was based on the length of the indentation's long diagonal, hardness values measured in this study were not affected by the hardness of the underlying ceramic.

The KHN data of three materials were analyzed respectively by a repeated measures ANOVA (SPSS Base 10.0 statistical software package). The independent variables were ceramic thickness (6 levels) and post-irradiation time (10 levels). All statistical tests were performed at $95 \%$ level of confidence. Statistical multiple comparison test on post-irradiation time was used to identify the time of reaching maximum hardness for each ceramic thickness with each material.

\section{RESULTS}

Light transmittance through machinable ceramic specimens with different thicknesses using visible light curing unit is shown in Fig. 2. The overlaid ceramic slice significantly reduced the intensity of the transmitted light. Intensity of the light without any thickness was $800 \mathrm{~mW} / \mathrm{cm}^{2}$, but a ceramic slice of only $0.5 \mathrm{~mm}$ thickness reduced the light intensity to $485 \mathrm{~mW} / \mathrm{cm}^{2}$. When ceramic thickness was increased to $2.5-3.0 \mathrm{~mm}$, less than $100 \mathrm{~mW} / \mathrm{cm}^{2}$ was transmitted. Ceramic thickness of 5.0 or $6.0 \mathrm{~mm}$ practically allowed no light to be transmitted through.

Table 2 shows the KHN values of the three dualcured resin cement materials irradiated through six different machinable ceramic thicknesses as a function of post-irradiation time. As for the surface hardness of NX2, it was too low to be measured by this tester when irradiated through ceramic thickness of $5 \mathrm{~mm}$. Regardless of ceramic thickness, the hardening behaviors of three resin cements showed similar results. In other words, an appreciable initial hardness was obtained after light irradiation, followed by a steep increase in the first 30 minutes, and thereafter hardness increased continually at a low rate up to the maximum KHN value.

Ceramic thickness and post-irradiation time had highly significant effects on KHN for the three evaluated materials $(p<0.001)$. In NX2, there was no statistically significant interaction between ceramic thickness and post-irradiation time $(p=0.178)$; however, this was not so for LMHV and VLIIHV $(p<0.001)$. The results of statistical analysis showed that on the whole, the three resin cements had a similar manner of decrease in KHN value as ceramic thickness increased. While KHN showed no significant differences between ceramic thicknesses of 0 and $1 \mathrm{~mm}$ (except for LMHV at post-irradiation time of 120 hours), every $1 \mathrm{~mm}$ increase of ceramic thickness generally resulted in a significant decrease in $\mathrm{KHN}$ value. In particular for NX2, when ceramic thickness was 4 and $5 \mathrm{~mm}$, KHN showed a more significant decrease.

When irradiated not through ceramic $(0 \mathrm{~mm})$ and at 120 hours of post-irradiation time, NX2 yielded the lowest KHN value of 33.5 among the three resin cements. Statistical multiple comparison test of mean hardness value at each time interval indicated that when NX2 was irradiated through ceramic thicknesses of 0 through $4 \mathrm{~mm}$, there was no significant increase in KHN value after eight hours of post-irradiation time. However, for ceramic thickness of $5 \mathrm{~mm}$, KHN value continued to increase up to 120 hours. As for LMHV, it showed the highest $\mathrm{KHN}$ value of 42.7 when irradiated not through ce-

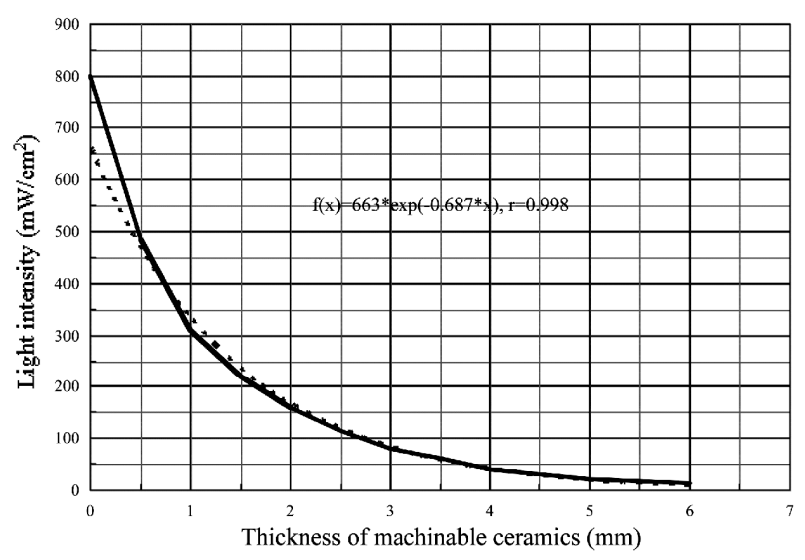

Fig. 2 Plot of light transmittance through machinable ceramic with different thicknesses (represented by solid line). Data fit the regression curve well (represented by broken line). 
Table 2 Knoop Hardness Number (KHN) of three dual-cured resin cements irradiated through six different thicknesses of machinable ceramic as a function of post-irradiation time

\begin{tabular}{|c|c|c|c|c|c|c|c|c|c|c|c|c|}
\hline \multirow{2}{*}{$\begin{array}{l}\text { Resin } \\
\text { cement }\end{array}$} & \multirow{2}{*}{$\begin{array}{c}\text { Ceramic } \\
\text { thickness } \\
(\mathrm{mm})\end{array}$} & \multicolumn{10}{|c|}{ Post-irradiation time (h) } & \multirow{2}{*}{\begin{tabular}{|c|} 
Mean \\
Difference \\
(120h-0h) \\
\end{tabular}} \\
\hline & & 0 & 0.5 & 1 & 2 & 4 & 8 & 24 & 48 & 72 & 120 & \\
\hline \multirow{6}{*}{$\begin{array}{c}\text { Linkmax } \\
\text { HV } \\
\text { (LMHV) }\end{array}$} & 0 & $26.4 \pm 0.4^{\mathrm{e}}$ & $32.2 \pm 0.6^{\mathrm{e}}$ & $34.3 \pm 0.6^{\mathrm{d}}$ & $35.4 \pm 0.3^{\mathrm{d}}$ & $37.7 \pm 0.3^{\mathrm{e}}$ & $40.0 \pm 0.5^{\mathrm{e}}$ & $41.4 \pm 1.1^{\mathrm{e}}$ & $42.0 \pm 0.3^{\mathrm{e}}$ & $42.4 \pm 0.7^{\mathrm{d}}$ & $42.7 \pm 0.5^{\mathrm{e}}$ & 16.3 \\
\hline & 1 & $5.6 \pm 0.3^{\mathrm{e}}$ & $31.9 \pm 0.3^{\mathrm{e}}$ & $33.8 \pm 0.5^{\mathrm{d}}$ & $35.2 \pm 0.4^{\mathrm{d}}$ & $37.6 \pm 0.7^{\mathrm{e}}$ & $39.8 \pm 0.6^{\mathrm{e}}$ & & & & & 16.0 \\
\hline & 2 & $.2 \pm 0.1^{\mathrm{d}}$ & $31.3 \pm 0.2^{\mathrm{d}}$ & $33.5 \pm 0.3^{\mathrm{d}}$ & $34.9 \pm 0.5^{\mathrm{d}}$ & $36.9 \pm 0.3^{\mathrm{d}}$ & $39.0 \pm 0.5^{\mathrm{d}}$ & $40.4 \pm 0.8^{\mathrm{d}}$ & $40.2 \pm 0.9^{\mathrm{d}}$ & $40.5 \pm 1.0^{\mathrm{c}}$ & 40.7 & 16.5 \\
\hline & 3 & $.6 \pm 0.7^{\mathrm{c}}$ & $30.2 \pm 0.4^{c}$ & $31.7 \pm 0.4^{c}$ & $33.4 \pm 0.8^{\mathrm{c}}$ & $35.8 \pm 0.6^{c}$ & $37.8 \pm 0.5^{c}$ & $39.1 \pm 0.3^{c}$ & $39.5 \pm 0.5^{c}$ & $39.6 \pm 1.1^{\mathrm{c}}$ & $39.9 \pm 0.9^{b}$ & 17.3 \\
\hline & 4 & $5 \pm 1.3^{b}$ & $24.8 \pm 0.8^{b}$ & $26.9 \pm 0.9^{b}$ & $28.4 \pm 1.6^{b}$ & $30.5 \pm 1.5^{\mathrm{b}}$ & $31.9 \pm 1.2^{\mathrm{b}}$ & $35.4 \pm 1.6^{\mathrm{b}}$ & $34.6 \pm 1.3^{\mathrm{b}}$ & $35.4 \pm 1.5^{\mathrm{b}}$ & $35.1=$ & 18.6 \\
\hline & 5 & $14.1 \pm 1.1^{\mathrm{a}}$ & $22.1 \pm 1.5^{\mathrm{a}}$ & $23.8 \pm 1.3^{\mathrm{a}}$ & $25.8 \pm 1.5^{\mathrm{a}}$ & $27.0 \pm 1.6^{\mathrm{a}}$ & $28.6 \pm 2.2^{\mathrm{a}}$ & $31.5 \pm 2.3^{\mathrm{a}}$ & $31.6 \pm 2.0^{\mathrm{a}}$ & $33.5 \pm 3.1^{\mathrm{a}}$ & $34.8 \pm 1.5^{\mathrm{a}}$ & 20.7 \\
\hline \multirow{6}{*}{$\begin{array}{c}\text { Nexus } 2 \\
\text { (NX2) }\end{array}$} & 0 & $.5 \pm 0.5^{\mathrm{d}}$ & $28.0 \pm 0.3^{\mathrm{e}}$ & $30.0 \pm 0.4^{\mathrm{e}}$ & $30.8 \pm 0.4^{\mathrm{e}}$ & $31.7 \pm 0.4^{\mathrm{e}}$ & $33.0 \pm 1.2^{\mathrm{e}}$ & $33.4 \pm 0.6^{\mathrm{e}}$ & $33.1 \pm 0.2^{\mathrm{e}}$ & $33.5 \pm 0.2^{\mathrm{e}}$ & $33.5 \pm 0.2^{\mathrm{d}}$ & 10.0 \\
\hline & 1 & $1.0 \pm 0.9^{\mathrm{d}}$ & $28.3 \pm 0.9^{e}$ & $30.0 \pm 0.3^{\mathrm{e}}$ & $31.1 \pm 0.8^{\mathrm{e}}$ & $32.1 \pm 0.6^{\mathrm{e}}$ & $33.2 \pm 0.8^{\mathrm{e}}$ & $33.4 \pm 0.8^{\mathrm{e}}$ & $33.2 \pm 0.5^{\mathrm{e}}$ & $33.5 \pm 0.7^{\mathrm{e}}$ & $33.5 \pm 1.1^{\mathrm{d}}$ & 9.5 \\
\hline & 2 & $1.8 \pm 0.4^{c}$ & $27.2 \pm 0.8^{\mathrm{d}}$ & $28.5 \pm 0.5^{\mathrm{d}}$ & $29.6 \pm 0.5^{\mathrm{d}}$ & $31.0 \pm 0.4^{\mathrm{d}}$ & $31.7 \pm 0.7^{\mathrm{d}}$ & $31.7 \pm 0.3^{\mathrm{d}}$ & $32.0 \pm 1.6^{\mathrm{d}}$ & $32.2 \pm 1.8^{\mathrm{d}}$ & $32.4 \pm 0.9^{d}$ & 10.6 \\
\hline & 3 & $0.2 \pm 0.6^{b}$ & $25.6 \pm 0.4^{\mathrm{c}}$ & $26.4 \pm 0.2^{c}$ & $27.6 \pm 0.4^{c}$ & $28.6 \pm 0.5^{c}$ & $29.6 \pm 0.9^{c}$ & $30.0 \pm 0.8^{c}$ & $30.1 \pm 0.6^{c}$ & $30.7 \pm 1.0^{\mathrm{c}}$ & $30.7 \pm 1.0^{c}$ & 10.5 \\
\hline & 4 & $3.6 \pm 1.2^{\mathrm{a}}$ & $18.6 \pm 1.1^{b}$ & $19.7 \pm 1.3^{b}$ & $20.4 \pm 1.4^{\mathrm{b}}$ & $21.3 \pm 1.4^{\mathrm{b}}$ & $22.0 \pm 1.4^{\mathrm{b}}$ & $23.9 \pm 1.6^{\mathrm{b}}$ & $24.1 \pm 1.8^{b}$ & $25.1 \pm 2.4^{b}$ & $24.8 \pm 2.6^{b}$ & 11.2 \\
\hline & 5 & - & $12.0 \pm 1.0^{a}$ & $12.8 \pm 1.2^{\mathrm{a}}$ & $13.3 \pm 1.0^{\mathrm{a}}$ & $13.7 \pm 1.2^{\mathrm{a}}$ & $14.0 \pm 1.1^{\mathrm{a}}$ & $15.1 \pm 1.4^{\mathrm{a}}$ & $14.6 \pm 1.9^{\mathrm{a}}$ & $15.3 \pm 1.9^{\mathrm{a}}$ & $17.3 \pm 2.5^{\mathrm{a}}$ & - \\
\hline \multirow{6}{*}{$\begin{array}{l}\text { Variolink } \\
\text { II HV } \\
\text { (VLIIHV) }\end{array}$} & 0 & $0 \pm 0$. & $32.6 \pm 0.5^{\mathrm{e}}$ & $34.2 \pm 0.4^{\mathrm{e}}$ & $36.0 \pm 0.2^{\mathrm{e}}$ & $37.8 \pm 0.4^{\mathrm{e}}$ & $39.5 \pm 0.2^{\mathrm{e}}$ & $40.5 \pm 0.5^{\mathrm{e}}$ & $40.6 \pm 0.4^{\mathrm{d}}$ & $40.9 \pm 0.5^{\mathrm{e}}$ & $40.3 \pm 0.5^{d}$ & 12.3 \\
\hline & 1 & $8.0 \pm 0.4^{\mathrm{e}}$ & $32.3 \pm 0.4^{\mathrm{e}}$ & $34.0 \pm 0.3^{\mathrm{e}}$ & $35.9 \pm 0.6^{\mathrm{e}}$ & $37.9 \pm 0.8^{\mathrm{e}}$ & $39.3 \pm 1.0^{\mathrm{e}}$ & $40.4 \pm 0.8^{\mathrm{e}}$ & $40.5 \pm 0.1^{\mathrm{d}}$ & $40.2 \pm 0.5^{\mathrm{e}}$ & $40.4 \pm 0.5^{\mathrm{d}}$ & 12.4 \\
\hline & 2 & $5.9 \pm 0.4^{\mathrm{d}}$ & $31.5 \pm 0.5^{\mathrm{d}}$ & $33.1 \pm 0.5^{\mathrm{d}}$ & $35.0 \pm 0.8^{\mathrm{d}}$ & $36.6 \pm 0.7^{\mathrm{d}}$ & $38.3 \pm 0.7^{\mathrm{d}}$ & $38.8 \pm 0.3^{\mathrm{d}}$ & $38.5 \pm 1.2^{c}$ & $38.5 \pm 0.6^{\mathrm{d}}$ & $38.6 \pm 1.0^{c}$ & 12.7 \\
\hline & 3 & $3.5 \pm 0.3^{c}$ & $29.8 \pm 0.4^{c}$ & $31.5 \pm 0.8^{c}$ & $33.6 \pm 0.5^{c}$ & $35.1 \pm 0.4^{\mathrm{c}}$ & $36.7 \pm 0.7^{\mathrm{c}}$ & $37.5 \pm 0.5^{c}$ & $37.9 \pm 0.3^{c}$ & $37.8 \pm 0.6^{\mathrm{c}}$ & $38.0 \pm 0.5^{c}$ & 14.5 \\
\hline & 4 & $7.4 \pm 0.9^{b}$ & $23.5 \pm 0.9^{b}$ & $25.5 \pm 1.1^{b}$ & $27.5 \pm 1.3^{\mathrm{b}}$ & $29.6 \pm 1.3^{b}$ & $30.9 \pm 1.5^{\mathrm{b}}$ & $35.0 \pm 1.6^{b}$ & $35.3 \pm 1.8^{b}$ & $35.3 \pm 1.5^{\mathrm{b}}$ & $35.2 \pm 2.3^{b}$ & 17.8 \\
\hline & 5 & $14.4 \pm 0.9^{\mathrm{a}}$ & $20.2 \pm 0.8^{\mathrm{a}}$ & $22.1 \pm 0.6^{\mathrm{a}}$ & $23.3 \pm 0.8^{\mathrm{a}}$ & $24.9 \pm 1.0^{\mathrm{a}}$ & $25.8 \pm 0.7^{\mathrm{a}}$ & $29.4 \pm 0.2^{\mathrm{a}}$ & $29.7 \pm 0.7^{\mathrm{a}}$ & $30.1 \pm 0.9^{\mathrm{a}}$ & $29.7 \pm 1.5^{\mathrm{a}}$ & 15.3 \\
\hline
\end{tabular}

Means with different superscript letters are significantly different between ceramic thicknesses at each post-irradiation time in the same resin cement $(p<0.05)$.

ramic and at 120 hours of post-irradiation time. Statistical analysis showed that for LMHV and VLIIHV, there were no significant increases in their KHN values after 24 hours of post-irradiation time regardless of ceramic thickness.

\section{DISCUSSION}

The hardness measurement of a thin layer of resin cement in this study simulated clinical conditions involving the cementation of different thicknesses of ceramic crowns - which are machine-milled using GN-I CAD/CAM ceramic blocks. It is well known that the light intensity reaching the cement is drastically reduced when light is transmitted through a ceramic or composite restoration. In the present study, light intensity decreased exponentially as a function of the restoration thickness [Light intensity $=663 * \exp \{(-0.687 *$ (ceramic thickness $)\}, \quad \mathrm{r}=$ $0.99]$, which was in agreement with previous studies $^{7,17)}$. As a result, an intensity of $800 \mathrm{~mW} / \mathrm{cm}^{2}$ was reduced to less than $100 \mathrm{~mW} / \mathrm{cm}^{2}$ when light was transmitted through machinable ceramic spacer exceeding $3.0 \mathrm{~mm}$. Resin composites are less capable to transmit light than a ceramic material of the same shade $^{6)}$. Therefore, longer irradiation times are recommended to compensate the diminished light intensity that reaches the resin cement ${ }^{9)}$.

Dual-cured resin luting cement has a more complicated polymerization process: one that involves an immediate light curing process and a delayed chemical curing process. In a previous investigation ${ }^{18)}$ on the reaction kinetics of five dual-cured resin cements through varying thicknesses of porcelain by chemical or light activation, it was found that cure speed during light exposure was five to 20 times faster than by chemical curing only. Moreover, it was only at a porcelain thickness of $4 \mathrm{~mm}$ that three resin cements showed a weak chemical polymerization reaction during light curing. In the light of these results, it may be suggested that a significant, chemically induced continuation of polymerization following light curing is difficult to achieve. This is because the initial light exposure will causes a rapid increase in viscosity, which hinders the migration of active radical components that are responsible for further chemically induced polymerization. Ironically, it is only when light intensity is weak that a small extent of chemical curing can occur. However, polymerization is not a momentary process, and cross-linking reactions continue even after the activating light has been removed.

Hardness of resinous materials measured at different stages of a polymerization reaction can be a useful indicator of the degree of conversion. Some studies indicated that hardness was closely correlated to small changes in polymer cross-linkages, and a small change in degree of conversion will lead to a large change in hardness ${ }^{19,20)}$. In a previous study ${ }^{20)}$, KHN proved to be a good predictor on the degree of conversion. In this study, however, absolute hardness value should not be used to compare the degree of conversion among the three resin cements used, because of effects arising from variations in mono- 
mer composition, filler content and type.

Three dual-cured resin cements used in this study showed similar hardening behavior in agreement with previous studies ${ }^{8,11-15)}$. This hardness development reflected a further "maturing" of the resin matrix with a continuation of cross-linking and methacrylate covalent bond formation after the initial flurry of activity by mixing or light-curing. Differences in hardening details among the materials could be attributed to compositional differences and extent of polymerization in resin matrix. In the present study, the hardening behaviors of the three materials might also well reflect their own polymerization characteristics through different ceramic thicknesses. The use of $800 \mathrm{~mW} / \mathrm{cm}^{2}$ might be the reason that the hardening behavior showed no significant differences between ceramic thicknesses of 0 and $1 \mathrm{~mm}$. At ceramic thicknesses of 4 and $5 \mathrm{~mm}$, the three materials showed slower increase in KHN value - thereby exhibiting near-chemical curing characteristics.

In Table 3, KHN values when irradiated not through ceramic $(0 \mathrm{~mm})$ at 120 hours of postirradiation time are used as control values (i.e., 42.7 for LMHV, 33.5 for NX2, and 40.3 for VLIIHV respectively). In addition, Table 3 provides the following data: KHN values at 0 hour (i.e., immediately after irradiation) and at 120 hours of postirradiation time, as well as difference between 0 hour and 120 hours for each ceramic thickness expressed as a percentage of control value to compare hardness characteristics in the three dual-cured resin cements. Although the NX2 material showed lower increase than VLIIHV material in KHN value between 0 hour and 120 hours at ceramic thicknesses 0 through 2 $\mathrm{mm}$ (9.5 through 10.6 for NX2 and 12.3 through 12.7 for VLIIHV in Table 2), they had similar increase in terms of relative percentage difference in KHN value between 0 hour and 120 hours of post-irradiation time $(28.4 \%$ through $31.6 \%$ for NX2 and $30.5 \%$ through $31.5 \%$ for VLIIHV in Table 3). As a means to indirectly evaluate the chemical curing capability of dual-cure resin cements between commercial brands, this method of measuring and calculating hardness could be a useful approach. With this method, the NX2 material showed the smallest percentage differences between 0 hour and 120 hours of post-irradiation time among the three resin cements at all ceramic thicknesses except for $2 \mathrm{~mm}$. These results indicated that the polymerization of NX2 was more dependent on the light condition, and little compensation was obtained from the chemical curing reaction as ceramic thickness increased. This observation ran contrary to the results of other studies $^{4,7)}$ which reported that NX2 had a relatively strong chemical curing capability. It was reported that even when composite thickness was $6 \mathrm{~mm}$, NX2 still had rather high hardness $(78.3 \%$ of control KHN). On the other hand, in this study, when NX2 was irradiated through ceramic thickness of $5 \mathrm{~mm}$, KHN value at 120 hours of post-irradiation time was only $51.6 \%$ of control KHN value (Table 3 ).

In this study, when the VLIIHV material was irradiated through ceramic thicknesses of 0,1 , and 2 $\mathrm{mm}$, the percentage differences in KHN value between 0 hour and 120 hours of post-irradiation time were smaller (i.e., $<31.5 \%$ ) compared with those for ceramic thicknesses of $3 \mathrm{~mm}$ and greater (i.e., $>36.0 \%)$. Likewise, it has also been reported that the chemical catalyst of VLIIHV improved the degree of conversion at ceramic thickness of $2 \mathrm{~mm}^{3)}$. However, these results were different from another study $^{7)}$ which reported that VLIIHV had a relatively weak chemical curing capability. This disparity of results could be because in the latter study ${ }^{7)}$, chemical curing capability was determined by the ratio of light catalyst/chemical catalyst. In the present study, the greatest increase occurred when irradiation was performed at ceramic thickness of $4 \mathrm{~mm}$ $(44.1 \%)$. It therefore seemed that VLIIHV was capable of being compensated by chemical curing, and that this capability increased as ceramic thickness in-

Table 3 Percentage of KHN value at 0 and 120 hours of post-irradiation time for each ceramic thickness compared with irradiated not through ceramic $(0 \mathrm{~mm})$ at 120 hours of post-irradiation time, which is used as a control $(42.7$ for LMHV, 33.5 for NX2, and 40.3 for VLIIHV, respectively)

\begin{tabular}{c|c|rrrrrc}
\hline \multirow{2}{*}{ Resin cement } & Post-irradiation time (h) & \multicolumn{5}{|c}{ Ceramic thickness $(\mathrm{mm})$} \\
\cline { 2 - 7 } & & \multicolumn{1}{|c}{0} & 1 & 2 & 3 & 4 & 5 \\
\hline \multirow{3}{*}{ LMHV } & 0 & 61.8 & 60.0 & 56.7 & 52.9 & 38.6 & 33.0 \\
& 120 & 100.0 & 97.4 & 95.3 & 93.4 & 82.2 & 81.5 \\
& Difference $(120 \mathrm{~h}-0 \mathrm{~h})$ & 38.2 & 37.4 & 38.6 & 40.5 & 43.6 & 48.5 \\
\hline \multirow{3}{*}{$\mathrm{NX} 2$} & 0 & 70.1 & 71.6 & 65.1 & 60.3 & 40.6 & - \\
& 120 & 100.0 & 100.0 & 96.7 & 91.6 & 74.0 & 51.6 \\
& Difference $(120 \mathrm{~h}-0 \mathrm{~h})$ & 29.9 & 28.4 & 31.6 & 31.3 & 33.4 & - \\
\hline \multirow{3}{*}{ VLIIHV } & 0 & 69.5 & 69.5 & 64.3 & 58.3 & 43.2 & 35.7 \\
& 120 & 100.0 & 100.0 & 95.8 & 94.3 & 87.3 & 73.7 \\
& Difference $(120 \mathrm{~h}-0 \mathrm{~h})$ & 30.5 & 30.5 & 31.5 & 36.0 & 44.1 & 38.0 \\
\hline
\end{tabular}


creased. LMHV had similar characteristics in KHN development as VLIIHV. However, LMHV seemed to have a stronger chemical curing capability because the relative percentage differences in KHN value between 0 hour and 120 hours were higher than VLIIHV regardless of ceramic thickness - except at $4 \mathrm{~mm}$ (Table 3).

\section{REFERENCES}

1) Blackman R, Barghi N, Duke E. Influence of ceramic thickness on the polymerization of light-cured resin cement. J Prosthet Dent 1990; 63: 295-300.

2) Hasegawa EA, Boyer DB, Chan DC. Hardening of dual-cured cements under composite resin inlays. J Prosthet Dent 1991; 66: 187-192.

3) Ozyesil AG, Usumez A, Gunduz B. The efficiency of different light sources to polymerize composite beneath a simulated ceramic restoration. J Prosthet Dent 2004; 91: 151-157.

4) Santos GC Jr, El-Mowafy OM, Rubo JH, Santos MJ. Hardening of dual-cure resin cements and a resin composite restorative cured with QTH and LED curing units. J Can Dent Assoc 2004; 70: 323-328.

5) Tashiro H, Inai N, Nikaido T, Tagami J. Effects of light intensity through resin inlays on the bond strength of dual-cured resin cement. J Adhes Dent 2004; 6: 233-238.

6) El-Badrawy WA, El-Mowafy OM. Chemical versus dual curing of resin inlay cements. J Prosthet Dent 1995; 73: 515-524.

7) El-Mowafy OM, Rubo MH. Influence of composite inlay/onlay thickness on hardening of dual-cured resin cements. J Can Dent Assoc 2000; 66: 147-147d.

8) Leung RL, Fan PL, Johnston WM. Post-irradiation polymerization of visible light-activated composite resin. J Dent Res 1983; 62: 363-365.

9) Rueggeberg FA, Caughman WF. The influence of light exposure on polymerization of dual-cure resin cements. Oper Dent 1993; 18: 48-55.

10) Caughman WF, Chan DC, Ruggeberg FA. Curing potential of dual-polymerizable resin cements in simulated clinical situations. J Prosthet Dent 2001; 85: 479484.

11) Hofmann N, Papsthart G, Hugo B, Klaiber B. Comparison of photo-activation versus chemical or dualcuring of resin-based luting cements regarding flexural strength, modulus and surface hardness. J Oral Rehabil 2001; 28: 1022-1028.

12) Yoshida K, Atsuta M. Post-irradiation hardening of dual-cured and light-cured resin cements through machinable ceramics. Am J Dent (in press).

13) Leung RL, Adishian SR, Fan PL. Postirradiation comparison of photoactivated composite resin cements. J Prosthet Dent 1985; 54: 645-649.

14) Watts DC, McNaughton V, Grant AA. The development of surface hardness in visible light-cured posterior composites. J Dent 1986; 14: 169-174.

15) Pilo R, Cardash HS. Post-irradiation polymerization of different anterior and posterior visible light-activated resin composites. Dent Mater 1992; 8: 299-304.

16) Darr AH, Jacobsen PH. Conversion of dual cure luting cements. J Oral Rehabil 1995; 22: 43-47.

17) Chan KC, Boyer DB. Curing light-activated cement through porcelain. J Dent Res 1989; 68: 476-480.

18) Lee IB, Um CM. Thermal analysis on the cure speed of dual cured resin cements under porcelain inlays. J Oral Rehabil 2001; 28: 186-197.

19) Ferracane JL. Correlation between hardness and degree of conversion during the setting reaction of unfilled dental restorative resin cements. Dent Mater 1985; 1: 11-14.

20) Rueggeberg FA, Craig RG. Correlation of parameters used to estimate monomer conversion in a light-cured composite. J Dent Res 1988; 67: 932-937. 